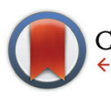

CrossMark

\& click for updates

Cite this: Dalton Trans., 2015, 44 1264

Received 10th September 2014 Accepted 11th November 2014

DOI: $10.1039 / c 4 d t 02767 a$

www.rsc.org/dalton

\section{Slow magnetic relaxation mechanisms in erbium SIMs $\uparrow$}

\author{
M. Ramos Silva, ${ }^{\star a}$ P. Martín-Ramos, ${ }^{a, b}$ J. T. Coutinho, ${ }^{c}$ L. C. J. Pereira, ${ }^{c}$ V. Lavín, ${ }^{d}$ \\ I. R. Martín, ${ }^{d}$ P. S. Pereira Silva ${ }^{a}$ and J. Martín-Gil ${ }^{b}$
}

The magnetic properties of two similar $\mathrm{Er}^{3+}$ complexes have been investigated. [Er(tpm) $\left.{ }_{3}(\mathrm{bipy})\right](\mathrm{Htpm}=$ 1,1,1-trifluoro-5,5-dimethyl-2,4-hexanedione and bipy = 2,2'-bipyridine) displays thermally activated slow relaxation of magnetisation under a zero direct-current (DC) field. Under an applied $H_{D C}$ field of $1000 \mathrm{G}$, $\left[\mathrm{Er}(\mathrm{tpm})_{3}(\mathrm{bipy})\right]$ exhibits two thermally activated processes with energy barriers of 9 and $40 \mathrm{~K}$, while [Er(tfa) (bipy) $(\mathrm{Htfa}=4,4,4$-trifluoro-1-(2-furyl)-1,3-butanedione) shows only one activated process with a barrier of $15 \mathrm{~K}$. Both compounds are luminescent in the solid state, emitting in the near IR region.

\section{Introduction}

Single-molecule magnets (SMMs) or molecular nanomagnets are isolated molecules or clusters that exhibit slow relaxation of the magnetisation and magnetic hysteresis at low temperatures. Several applications can be envisaged for these tiny magnets, such as ultra-high-density magnetic information storage, molecular spintronics or quantum computing ${ }^{1,2}$ and, a lot of effort has been put into their research. The main shortcoming to be overcome is the very low temperatures at which SMMs work. The origin of the single-molecule magnetism is in the energy barrier that prevents the reversal of the magnetic moment once the external field is removed. Small energy barriers only allow low working temperatures. In 3d-SMMs the energy barrier amounts to $|D| \cdot S^{2}$ where $D$ is related to the magnetic anisotropy and $S$ is the total magnetic moment of the complex/cluster. Efforts to increase both $D$ and $S$ in 3d metal

\footnotetext{
${ }^{a}$ CEMDRX, Physics Department, Universidade de Coimbra, Rua Larga, P-3004-516 Coimbra, Portugal. E-mail: manuela@pollux.fis.uc.pt; http://pollux.fis.uc.pt/; Fax: +351 239 829158; Tel: +351 239410648

${ }^{b}$ Advanced Materials Laboratory, ETSIIAA, Universidad de Valladolid, Avenida de Madrid 44, 34004 Palencia, Spain

${ }^{c}$ Solid State Group, UCQR, IST/CTN, Instituto Superior Técnico, UTL, Estrada Nacional 10, km 139.7, 2695-066 Bobadela LRS, Portugal

${ }^{d}$ Department of Physics and MALTA Consolider Team, Universidad de La Laguna, E-38200 San Cristóbal de La Laguna, Santa Cruz de Tenerife, Spain

$\dagger$ Electronic supplementary information (ESI) available: Vibrational characterization (FTIR and Raman), ${ }^{1} \mathrm{H}-\mathrm{NMR}$ and ${ }^{13} \mathrm{C}-\mathrm{NMR}$ spectroscopic data, TG/DTG/ DTA analysis, UV-Vis absorption and UV-Vis-NIR diffuse reflectance spectra, emission spectrum in the visible region, excitation spectrum, ligand-associated PL decay and static magnetic measurements for the $\left[\operatorname{Er}(\mathrm{tfa})_{3}(\mathrm{bipy})\right]$ complex. Additional AC susceptibility measurements for both $\left[\operatorname{Er}(\mathrm{tfa})_{3}(\mathrm{bipy})\right]$ and $\left[\operatorname{Er}(\operatorname{tpm})_{3}(\right.$ bipy $\left.)\right]$ samples. CCDC 1010428 for $\left[\operatorname{Er}(\operatorname{tfa})_{3}(\right.$ bipy $\left.)\right]$. For ESI and crystallographic data in CIF or other electronic format see DOI: 10.1039/c4dt02767a
}

clusters have failed $^{3}$ and researchers have shifted their attention to complexes containing lanthanide/actinide ions. The $\mathrm{f}$ electrons of the lanthanide ions are mostly unperturbed by the coordinating organic ligands (that interact mainly with the $5 \mathrm{~s}$ and $5 \mathrm{p}$ electrons), thus a large orbital angular momentum is preserved. Such unquenched angular momentum ensures intrinsic magnetic anisotropy and large magnetic moments, and a thermal energy barrier of $530 \mathrm{~K}$ has been reported for a $\mathrm{Dy}^{3+}$ cluster. $^{4}$ Even single lanthanide ions can exhibit energy barriers up to $915 \mathrm{~K} .^{5}$

There are few of these single-ion magnets, with $\mathrm{Er}^{3+}$, reported in the literature; some examples are even found where $\mathrm{Er}^{3+}$ complexes, isostructural to other lanthanide complexes, fail to show slow magnetic relaxation while their counterparts do. ${ }^{6}$ There are other reported examples of single $\mathrm{Er}^{3+}$ complexes, where a field induced slow magnetic relaxation is observed. ${ }^{7,8}$ That is also the case with $\left[\operatorname{Er}(\mathrm{tfa})_{3}(\mathrm{bipy})\right]$, a new compound whose synthesis, structure, luminescence and magnetic properties are reported in this paper.

Far less common is the display of slow magnetic relaxation at zero DC field: to the best of our knowledge only two cases have been reported for $\mathrm{Er}^{3+}$ so far. ${ }^{9-11}$

We present here the magnetic properties of $\left[\operatorname{Er}(\operatorname{tpm})_{3}(\right.$ bipy $\left.)\right]$, a third example of an $\mathrm{Er}^{3+}$ SIM, that exhibits a magnetic hysteresis curve. Its synthesis, structure and characterization (vibrational, thermal and luminescent) have been already reported in a previous article. ${ }^{12}$

The two compounds studied can be considered bifunctional, since they combine both magnetic and luminescence properties: the organic ligands that coordinate the lanthanide ion not only promote a suitable environment for the existence of an anisotropic barrier to magnetization reversal but also absorb ultraviolet light, transferring the energy to the lanthanide ion that re-emits it as near infrared (NIR) radiation. 


\section{Experimental section}

\section{Materials, synthesis and analytical data}

All reagents and solvents employed were commercially available and used as supplied without further purification. All the procedures for complex preparation were carried out under nitrogen and using dry reagents to avoid the presence of water and oxygen, which can quench metal photoluminescence (PL).

Tris(4,4,4-trifluoro-1-(2-furyl)-1,3-butanedionate)mono(2,2'bipyridine)erbium(III) was obtained as follows: under stirring, a 4,4,4-trifluoro-1-(2-furyl)-1,3-butanedione (3 $\mathrm{mmol}$ ) methanol solution $(20 \mathrm{ml})$ was added to $1 \mathrm{mmol}$ of $\operatorname{Er}\left(\mathrm{NO}_{3}\right)_{3} \cdot 5 \mathrm{H}_{2} \mathrm{O}$ in methanol. The mixture was neutralized by adding potassium methoxide $(3 \mathrm{mmol})$ dropwise under vigorous stirring until potassium nitrate precipitated. $\mathrm{KNO}_{3}$ was removed by decanting, and 2,2'-bipyridine (1 $\mathrm{mmol})$ was finally added. The mixture was heated to $75{ }^{\circ} \mathrm{C}$ and stirred overnight, then washed with dioxane, and finally dried in a vacuum to give the product in 90-95\% yield (based on Er). Crystals suitable for $\mathrm{X}$-ray analysis were obtained by slow evaporation of a methanoldioxane solution at RT.

[Er(tfa) ${ }_{3}\left(\right.$ bipy)]: Chemical formula: $\mathrm{C}_{34} \mathrm{H}_{20} \mathrm{ErF}_{9} \mathrm{~N}_{2} \mathrm{O}_{9} . M_{\mathrm{W}}$ : 938.77. Anal. Calcd for $\mathrm{C}_{34} \mathrm{H}_{20} \mathrm{ErF}_{9} \mathrm{~N}_{2} \mathrm{O}_{9}$ : C, 43.50; H, 2.15; Er, 17.82; F, 18.21; N, 2.98; O, 15.34. Found: C, 44.01; H, 2.16; N, 2.88 (Scheme 1).

\section{Physical and spectroscopic measurements}

The C, H, N elemental analyses were conducted using a Perkin Elmer CHN 2400 apparatus.

Differential scanning calorimetry (DSC) data were obtained on a DSC TA instrument model Q100 v.9.0 with a heating rate of $10{ }^{\circ} \mathrm{C} \mathrm{min}^{-1}$ under a $\mathrm{N}_{2}$ atmsphere. Thermogravimetric and differential thermal analyses were carried out under an inert atmosphere with a Perkin Elmer Pyris Diamond TGA/DTA, by heating $3 \mathrm{mg}$ of the sample in a slow stream of $\mathrm{N}_{2}\left(40 \mathrm{~mL} \mathrm{~min}^{-1}\right)$ from room temperature up to $300{ }^{\circ} \mathrm{C}$, with a heating rate of $10{ }^{\circ} \mathrm{C} \min ^{-1}$.

The infrared spectrum was recorded with a Thermo Nicolet 380 FT-IR spectrometer in KBr pellets.

The Raman spectrum was recorded with a FT-Raman Bruker FRA106 using a near-IR (Nd: YAG, $1064.1 \mathrm{~nm})$ laser to excite the sample.

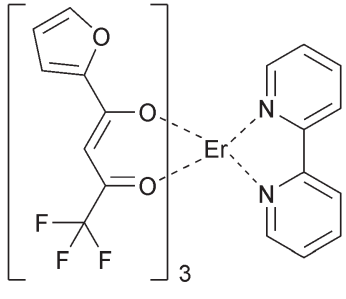

$\left[\mathrm{Er}(\mathrm{tfa})_{3}(\mathrm{bipy})\right]$

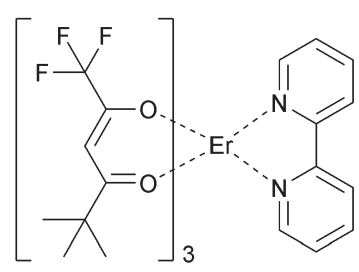

$\left[\mathrm{Er}(\mathrm{tpm})_{3}(\right.$ bipy) $]$
Scheme 1 Chemical structures of $\left[\mathrm{Er}(\mathrm{tfa})_{3}(\mathrm{bipy})\right]$ (left) and $\left[\mathrm{Er}(\mathrm{tpm})_{3}(\mathrm{bipy})\right]$ (right).
The NMR spectra were registered from a deuterated chloroform solution $\left(\mathrm{CDCl}_{3}\right)$ using a $400 \mathrm{MHz} \mathrm{NMR}$ spectrometer from Varian model Mercury 400 (9.4 Tesla) at $400.123 \mathrm{MHz}$ and at $100.6 \mathrm{MHz}$ for ${ }^{1} \mathrm{H}-\mathrm{NMR}$ and ${ }^{13} \mathrm{C}-\mathrm{NMR}$, respectively.

The crystal structure was elucidated by X-ray diffraction analysis. The powder diffractogram of $\left[\operatorname{Er}(\mathrm{tfa})_{3}(\mathrm{bipy})\right]$ was obtained using an ENRAF-NONIUS FR590 powder diffractometer equipped with an INEL120 detector (Debye-Scherrer geometry). The powder was used to fill a glass capillary, which was slowly rotating upon data collection.

For the determination of the crystal structure by X-ray diffraction, a crystal of $\left[\operatorname{Er}(\mathrm{tfa})_{3}\right.$ (bipy)] was glued to a glass fibre and mounted on a Bruker APEX II diffractometer. Diffraction data were collected at room temperature 293(2) K using graphite monochromated MoK $\alpha(\lambda=0.71073 \AA)$. Absorption corrections were made using SADABS. ${ }^{13}$ The structure was solved by direct methods using SHELXS- $97^{14}$ and refined anisotropically (non-H atoms) by full-matrix least-squares on $F^{2}$ using the SHELXL-97 program ${ }^{14}$ (Table 1). PLATON ${ }^{15}$ was used to analyse the structure and figure plotting. All $\mathrm{CF}_{3}$ groups show signs of disorder with large displacement ellipsoids. In one of the molecules such groups could be refined over two positions, with $\mathrm{F}$ atoms refined isotropically, with $60 / 40 \%$ occupation. In the other two molecules, the furyl rings were disordered due to a $180^{\circ}$ rotation around the $\mathrm{C}-\mathrm{C}$ bond that attaches the ring to the $\beta$-diketonate moiety.

The optical absorption and diffuse reflectance spectra of the material were measured at room temperature in a solution and in powder, respectively: the $200-800 \mathrm{~nm}$ range absorption spectrum was recorded with a spectrophotometer (Hitachi

Table 1 Crystal data and structure refinement

$\begin{array}{ll}\text { Complex } & {\left[\mathrm{Er}(\mathrm{tfa})_{3}(\mathrm{bipy})\right]} \\ \text { Empirical formula } & \mathrm{C}_{34} \mathrm{H}_{20} \mathrm{ErF}_{9} \mathrm{~N}_{2} \mathrm{O}_{9} \\ \text { Formula weight } & 938.78 \\ \text { Temperature } & 293(2) \mathrm{K} \\ \text { Wavelength } & 0.71073 \AA \\ \text { Crystal system } & \text { Monoclinic } \\ \text { Space group } & P 2{ }_{1} / c \\ a & 10.124(3) \AA \\ b & 16.991(6) \AA \\ c & 21.418(7) \AA \\ \alpha & 90^{\circ} \\ \beta & 104.820(7)^{\circ} \\ \gamma & 90^{\circ} \\ \text { Volume } & 3562(2) \AA^{3} \\ Z & 4 \\ \text { Density (calculated) } & 1.751 \mathrm{~g} \mathrm{~cm}^{-3} \\ \text { Absorption coefficient } & 2.459 \mathrm{~mm}^{-1} \\ F(000) & 1836.0 \\ \text { Crystal size } & 0.22 \times 0.15 \times 0.10 \mathrm{~mm}^{3} \\ \theta \text { range for data collection } & 1.97-28.36^{\circ} \\ \text { Index ranges } & -13<h<13 ;-22<k<22 ;-28<l<28 \\ \text { Reflections collected } & 58504 \\ \text { Independent reflections } & 8884 \\ \text { Completeness to } 2 \theta=51^{\circ} & 99.6 \% \\ \text { Refinement method } & \text { Full matrix LS on } F^{2} \\ \text { Data/restraints/parameters } & 8884 / 0 / 562 \\ \text { Goodness-of-fit on } F^{2} & 0.954 \\ \text { Final } R \text { indices }[I>2 \sigma(I)] & R=0.0474 ; \mathrm{w} R=0.0916 \\ R \text { indices (all data) } & R=0.1101 ; \mathrm{w} R=0.1133 \\ \text { Largest diff. peak and hole } & -0.694 / 1.190 \\ & \end{array}$


U-2010) in methanol diluted solutions $\left(10^{-5} \mathrm{M}\right.$ and $\left.10^{-3} \mathrm{M}\right)$, and the UV-Vis-NIR diffuse reflectance spectrum in the range from 200 to $1800 \mathrm{~nm}$ was measured using an integrating sphere coupled to a spectrophotometer (Agilent Cary 5000) in a powder form.

The visible photoluminescence spectrum was excited with a $405 \mathrm{~nm}$ laser, and collected with a 0.303 focal length Shamrock spectrometer with an Andor Newton cooled CCD camera. The ligand lifetimes have been measured using an Edinburgh Instruments LifeSpec II fluorescence spectrometer, exciting the complex at $\lambda=405 \mathrm{~nm}$ with an Edinburgh Instruments EPL-405 picosecond pulsed diode laser working in the $\mathrm{MHz}$ repetition range (temporal pulse width at half maximum about 80 ps), and using Edinburgh Instruments F900 acquisition software.

NIR photoluminescence spectra were measured by exciting at the ligand absorption at ca. $337 \mathrm{~nm}$ with a $\mathrm{N}_{2}$ laser, and at $532 \mathrm{~nm}$ resonantly with a ${ }^{4} \mathrm{I}_{15 / 2} \rightarrow{ }^{2} \mathrm{H}_{11 / 2}$ transition of the $\mathrm{Er}^{3+}$ absorption using a $500 \mathrm{~mW} \mathrm{cw}$ laser diode. The emission was analyzed with a Peltier-cooled InGaAs Hamamatsu pin photodiode G5851-21 at $-25{ }^{\circ} \mathrm{C}$ and a Horiba Jobin Yvon Triax 180 monochromator. For the excitation spectra, a xenon arc lamp with a $1 / 8 \mathrm{~m}$ Oriel monochromator was used, detecting the emission at a fixed wavelength $(1530 \mathrm{~nm})$ using the Triax 180 monochromator. The NIR photoluminescence time decay measurement was carried out upon excitation at $980 \mathrm{~nm}$ resonantly with ${ }^{4} \mathrm{I}_{15 / 2} \rightarrow{ }^{2} \mathrm{I}_{11 / 2}$ with an OPO (EKSPLA NT 342/3/UVE) at a $10 \mathrm{~Hz}$ repetition rate and recorded using a Tektronix (model 3840) oscilloscope. All spectra have been measured at room temperature and have been corrected by the spectral response of the experimental setup.

\section{Magnetic measurements}

The magnetic susceptibility under several magnetic fields was measured with a S700X SQUID magnetometer (Cryogenic Ltd) in the temperature range $4-300 \mathrm{~K}$ and assuming a diamagnetic contribution of $-4.592 \times 10^{-4}$ and $-5.063 \times 10^{-4} \mathrm{emu} \mathrm{mol}^{-1}$, for $\left[\operatorname{Er}(\mathrm{tfa})_{3}(\right.$ bipy) $]$ and $\left[\operatorname{Er}(\operatorname{tpm})_{3}(\right.$ bipy)$]$, respectively (estimated from tabulated Pascal constants). Field dependence of the magnetization was measured up to $5 \mathrm{~T}$ at different fixed temperatures from $1.7 \mathrm{~K}$ to $10 \mathrm{~K}$. AC measurements were taken using a MagLab 2000 system (Oxford Instruments) with an AC field of 5 Oe. Temperature dependence of AC magnetic susceptibility was measured in the $10-10000 \mathrm{~Hz}$ frequency range under a zero and 1000 Oe static DC field. Additional isothermal AC susceptibility measurements, $\chi_{\mathrm{AC}}=f(\omega)$, were taken in the 10-10 $000 \mathrm{~Hz}$ frequency range, within 1.7 and $7 \mathrm{~K}$.

\section{Results and discussion}

\section{Structural discussion}

The pinkish compound $\left[\operatorname{Er}(\mathrm{tfa})_{3}\right.$ (bipy)] crystallizes in the $P 2_{1} / c$ space group of a monoclinic system with four symmetry equivalent complexes in each unit cell (Fig. 1, Table 1). In each complex, three negatively charged furyl- $\beta$-diketonates coordi-

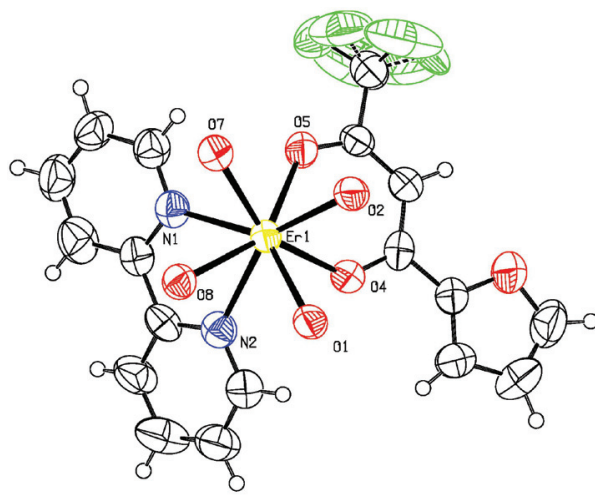

Fig. 1 ORTEP plot of $\left[\mathrm{Er}(\mathrm{tfa})_{3}(\mathrm{bipy})\right]$. For clarity reasons, only one of the three 4,4,4-trifluoro-1-(2-furyl)-1,3-butanedionate ligands is fully shown.

Table 2 Selected distances and angles $\left(\AA^{\circ},{ }^{\circ}\right)$

\begin{tabular}{llll}
\hline Bond & Distance & Bonds & Angles \\
\hline Er1-O1 & $2.295(3)$ & O1-Er1-O5 & $138.23(12)$ \\
Er1-O2 & $2.289(3)$ & O1-Er1-O7 & $119.56(13)$ \\
Er1-O4 & $2.300(4)$ & O2-Er1-O4 & $83.00(13)$ \\
Er1-O5 & $2.333(3)$ & O2-Er1-O5 & $76.06(13)$ \\
Er1-O7 & $2.309(4)$ & O4-Er1-O7 & $151.76(12)$ \\
Er1-O8 & $2.310(3)$ & O1-Er1-N1 & $141.41(13)$ \\
Er1-N1 & $2.512(4)$ & O8-Er1-N1 & $79.00(13)$ \\
Er1-N2 & $2.525(4)$ & O8-Er1-N2 & $70.57(12)$ \\
& & O7-Er1-N2 & $131.13(13)$
\end{tabular}

nate the lanthanide ion through the $\mathrm{O}$ atoms of the central aromatic moiety. One 2,2'-bipyridine molecule also coordinates each lanthanide ion through the $\mathrm{N}$ atoms. The $\mathrm{Er}^{3+}$ ions are therefore surrounded by six $\mathrm{O}$ atoms and two $\mathrm{N}$ atoms in a distorted antiprismatic geometry (Fig. 1, Table 1). The top and bottom anti-faces are nearly parallel $\left[2.38(14)^{\circ}\right.$ between their mean planes]. The lanthanide ion is approximately at the center of the anti-prism with a distance of 1.3756(2) and 1.1624(2) $\AA$ from the face containing the $\mathrm{N}$ atoms and to the opposite face, respectively (Table 2).

To characterize the degree of distortion of the square antiprism we have calculated the $\alpha$ and the skew angle $\phi{ }^{16}$

$\alpha$ is defined as the angle between the $\mathrm{C} 4$ axis and the direction of the Er-N,O vectors (Fig. 2). Because of the prism distortion we considered the line connecting Er1 and the centroid of the $(\mathrm{O} 1, \mathrm{O} 2, \mathrm{O} 7, \mathrm{O} 8)$ square face as the approximate $\mathrm{C} 4$ axis and then we computed the angle between this axis and the Er-N,O vectors. For the calculation of $\phi$ we first projected Er1, N1, N2, $\mathrm{O} 4$ and $\mathrm{O} 5$ to the mean plane of the most regular face $(\mathrm{O} 1, \mathrm{O} 2$, O7,O8) and then calculated the angle between the projected vectors (Fig. 2). The total sum of the deviations from the ideal values for $\phi$ and $\alpha$ are 50 and 28 $8^{\circ}$, respectively (Tables 3 and 4).

In the 2,2'-bipyridine ligand the two aromatic rings are only slightly rotated with a $5^{\circ}$ dihedral angle between their mean planes. In the crystal structure, the complexes pack in dimers with the bipyridine ring systems exhibiting a short centroid.... centroid ${ }^{\mathrm{i}}$ distance $3.749(4) \AA$ (i: $\left.-x,-y,-z\right)$. 
(a)
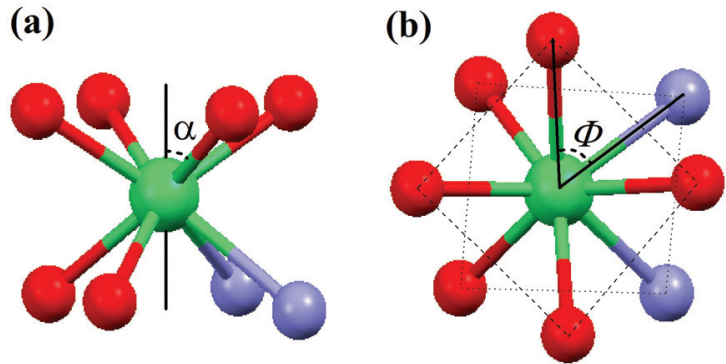

Fig. 2 Definition of $\alpha$ and $\phi$ in the square-antiprismatic geometry.

Table 3 Relevant structural parameters in square anti-prism geometry, $\alpha$ angle

\begin{tabular}{lll}
\hline$\alpha$ angle $\left(^{\circ}\right)$ & {$\left[\operatorname{Er}(\text { tfa })_{3}(\right.$ bipy $\left.)\right]$} & $\begin{array}{l}\text { Equivalent angles } \\
\text { in }\left[\operatorname{Er}(\operatorname{tpm})_{3}(\text { bipy })\right]^{12}\end{array}$ \\
\hline O8 & $58.06(2)$ & 59.74 \\
N1 & $53.71(2)$ & 57.74 \\
O7 & $60.22(2)$ & 55.43 \\
O5 & $53.86(2)$ & 54.13 \\
O2 & $60.93(2)$ & 63.69 \\
O4 & $53.27(2)$ & 51.98 \\
O1 & $59.38(2)$ & 59.40 \\
N2 & $59.76(2)$ & 52.64 \\
Sum of deviation & 28.0 & 27.8 \\
to ideal 54.74 & &
\end{tabular}

Table 4 Relevant structural parameters in square anti-prism geometry, $\phi$ angle

\begin{tabular}{lll}
\hline$\phi$ angle $\left(^{\circ}\right)$ & {$\left[\operatorname{Er}(\mathrm{tfa})_{3}(\right.$ bipy $\left.)\right]$} & $\begin{array}{l}\text { Equivalent angles } \\
\text { in }\left[\operatorname{Er}(\operatorname{tpm})_{3}(\text { bipy })\right]^{12}\end{array}$ \\
\hline O8-Er1-N1 & $43.89(2)$ & 33.44 \\
N1-Er1-O7 & $43.13(2)$ & 54.73 \\
O7-Er1-O5 & $52.83(2)$ & 36.09 \\
O5-Er1-O2 & $41.49(2)$ & 51.78 \\
O2-Er1-O4 & $52.67(2)$ & 43.08 \\
O4-Er1-O1 & $36.15(2)$ & 53.92 \\
O1-Er1-N2 & $54.59(2)$ & 39.42 \\
N2-Er1-O8 & $35.44(2)$ & 48.04 \\
Sum of deviation & 50.0 & 56.4 \\
to ideal 45 & &
\end{tabular}

\section{X-ray powder diffraction}

Fig. 3 shows the experimental diffraction pattern of the complex and the simulated powder pattern from the single crystal structure using PLATON. ${ }^{15}$ There is an excellent match between the simulated and the experimental diffractograms: the peaks appear at the predicted theta angles at the same relative intensities. The experimental diffractogram shows a background higher for low theta angles as expected from the diffuse scattering of the X-rays by glass and air, a common characteristic when using rotating capillaries in a DebyeScherrer geometry. Powder diffraction shows that all the materials synthesized in the crystalline form correspond to the same structure as the small single crystals used for singlecrystal X-ray diffraction.

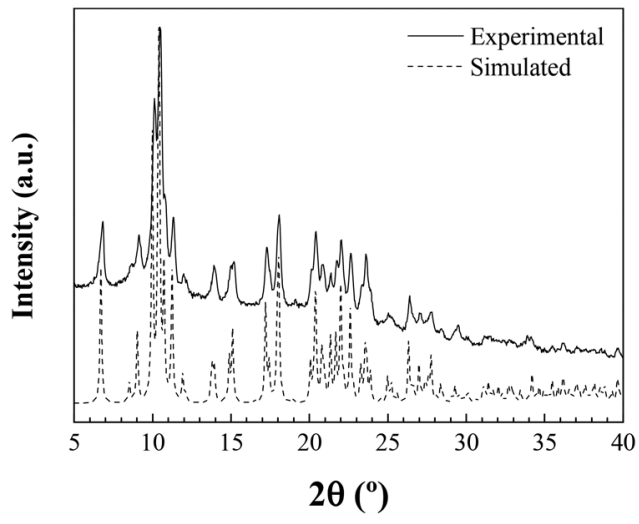

Fig. 3 Experimental versus calculated X-ray powder patterns for $\left[\mathrm{Er}(\mathrm{tfa})_{3}(\mathrm{bipy})\right]$.

\section{Thermal analysis}

The TG curve of the $\left[\operatorname{Er}(\operatorname{tfa})_{3}(\right.$ bipy $\left.)\right]$ complex (Fig. S4 $\dagger$ ) shows an initial weight loss of $c a .12 \%$ below $110{ }^{\circ} \mathrm{C}$ (associated to a peak at around $105{ }^{\circ} \mathrm{C}$ in the DTG curve) and a subsequent weight loss of $c a .5 \%$ in the $110-240{ }^{\circ} \mathrm{C}$ range (corresponding to an endothermic effect at $185{ }^{\circ} \mathrm{C}$ in the DTA). Both weight losses can be referred to a gradual loss of 2,2'-bipyridine ligand (which accounts for $\sim 17 \%$ of the complex $M_{\mathrm{W}}$ ). The final decomposition of the complex, associated with tfa $\beta$-diketonate ligand degradation, starts at $250{ }^{\circ} \mathrm{C}$ and reaches a maximum at $280{ }^{\circ} \mathrm{C}$. The DSC curve (Fig. 4) shows a great endothermic effect at $200{ }^{\circ} \mathrm{C}$ (corresponding to the N,N-donor loss), followed by a smaller endotherm at $280{ }^{\circ} \mathrm{C}$ (ascribable to the ultimate complex decomposition).

\section{Optical properties}

Inspecting the UV-Vis absorption and UV-Vis-NIR diffuse reflectance spectra of $\left[\operatorname{Er}(\mathrm{tfa})_{3}(\mathrm{bipy})\right]$, it is clear that the main absorption takes place when the incident wavelengths are in the ultraviolet region of 230 to $400 \mathrm{~nm}$, due to the organic ligands that coordinate the lanthanide (see Fig. S5 $†$ ). Measurements of the NIR emission of the $\mathrm{Er}^{3+}:{ }^{4} \mathrm{I}_{13 / 2} \rightarrow{ }^{4} \mathrm{I}_{15 / 2}$ transition (1.5 $\mu \mathrm{m}$ emission) (Fig. 5) under excitation of the organic ligand at $\lambda=337 \mathrm{~nm}$ and under direct excitation of the $\mathrm{Er}^{3+}:{ }^{2} \mathrm{H}_{11 / 2}$ state $(532 \mathrm{~nm})$, for comparison purposes, yield the

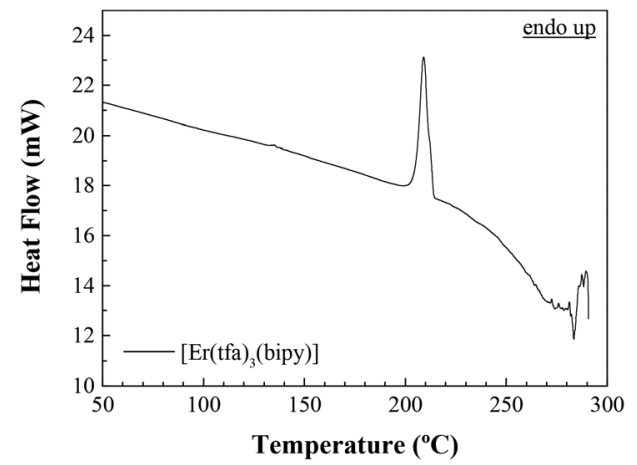

Fig. 4 DSC data for $\left[\operatorname{Er}(\mathrm{tfa})_{3}(\mathrm{bipy})\right]$. 


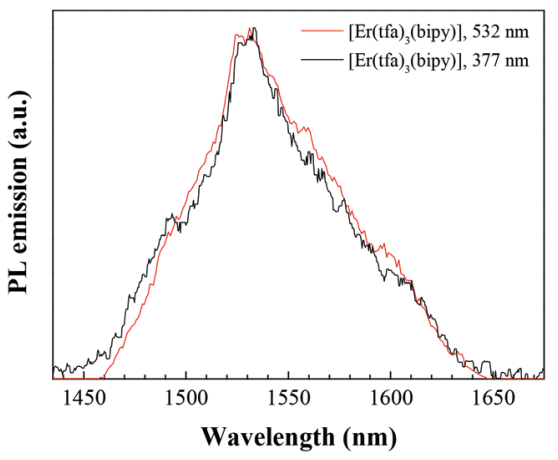

Fig. $5 \mathrm{PL}$ emission in the NIR region upon direct excitation of $\mathrm{Er}^{3+}$ at $\lambda=532 \mathrm{~nm}$ (red) and exciting the organic ligands at $\lambda=337 \mathrm{~nm}$ (black).

same results: in both cases the emission band shows a maximum at $1532 \mathrm{~nm}$ and some structure related with the Stark energy levels and electron population distributions of ${ }^{4} \mathrm{I}_{13 / 2}$ and ${ }^{4} \mathrm{I}_{15 / 2}$ multiplets, but the intensity is higher for the $337 \mathrm{~nm}$ excitation. The sensitization by the antenna effect is therefore effective: ligands absorb the energy and transfer it to the $\mathrm{Er}^{3+}$ ion (see the excitation spectrum in Fig. S7 $\dagger$ ). As a result of this energy transfer, the visible emission of the ligands is strongly reduced in the $\mathrm{Er}^{3+}$ complex and at the same time, the characteristic NIR emission of the $\mathrm{Er}^{3+}:{ }^{4} \mathrm{I}_{13 / 2} \rightarrow{ }^{4} \mathrm{I}_{15 / 2}$ transition is favored.

\section{Lifetime measurements}

The PL decay of the organic ligands has been measured after excitation with a high-repetition rate pulsed picosecond laser at $\lambda=405 \mathrm{~nm}$ (see Fig. $\mathrm{S} 8 \dagger$ ), the same wavelength chosen for the visible PL emission spectrum. Under this direct excitation, ground state absorption $\mathrm{S}_{0} \rightarrow \mathrm{S}_{1}$ in the ligand moiety occurs, followed by fast vibrational relaxation to the lowest excited singlet level, from which it can relax radiatively emitting a photon at around $440 \mathrm{~nm}$ or it may undergo intersystem crossing to the triplet level due to spin reorientation (from which subsequent resonance energy transfer to $\mathrm{Er}^{3+}$ may take place). The studied $S_{1} \rightarrow S_{0}$ radiative decay time - determined using FAST® software for the deconvolution of the instrument response function (IRF) and the exponential component analysis - is $0.75 \mathrm{~ns}, v s$. $2.21 \mathrm{~ns}$ for the non-coordinated ligands. This shortening of the ligand lifetime value is indicative of an efficient antenna effect, that is, the excited states are efficiently transferred to the $\mathrm{Er}^{3+}$ through intersystem crossing (ISC) and subsequent resonance energy transfer (RET).

Regarding the NIR emission $\left(\mathrm{Er}^{3+}:{ }^{4} \mathrm{I}_{13 / 2} \rightarrow{ }^{4} \mathrm{I}_{15 / 2}\right.$ transition), a single-exponential decay is obtained (Fig. 6), which gives rise to a lifetime of $1.24 \mu \mathrm{s}$. This value, typical of lanthanide complexes (and far smaller than the emission decay time of the isolated ion, $\tau \approx 8 \mathrm{~ms}$ ), is due to vibronic coupling with high energy $\mathrm{C}-\mathrm{H}$ stretching vibrations in the neighbourhood of the $\mathrm{Er}^{3+}$ ion (originated from the remaining non-fluorinated part of the ligands), which lead to quenching of the excited state (because of the relatively small energy gap between the excited state ${ }^{4} \mathrm{I}_{13 / 2}$ and the ground state). Nonetheless, it must be

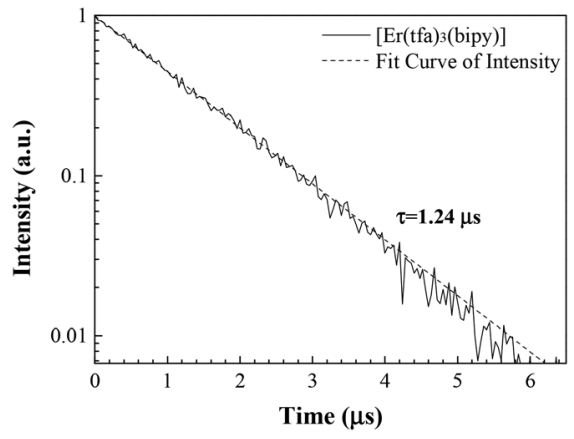

Fig. 6 Decay curve of the $\mathrm{Er}^{4} \mathrm{I}_{13 / 2} \rightarrow{ }^{4} \mathrm{I}_{15 / 2}$ transition (solid line) corresponding to the emission at $\lambda=1540 \mathrm{~nm}$. The fit corresponds to a decay curve with a lifetime of $1.24 \mu \mathrm{s}$ (dashed line).

noted that this complex shows a significant reduction of the non-radiative losses caused by $\mathrm{O}-\mathrm{H}$ and $\mathrm{N}-\mathrm{H}$ oscillators, which have the most deleterious effects on the emission, and that the partial fluorination of the $\beta$-diketonates leads to an increase in the lifetime in comparison with analogous non-fluorinated complexes, which show lifetime values around $1 \mu \mathrm{s} .^{8}$

The decays obtained after $980 \mathrm{~nm}$ excitation show single exponential behaviour, which confirms a unique and consistent coordination environment around the lanthanide ion. ${ }^{17}$

\section{Magnetic measurements}

Static magnetic properties. The variable temperature DC magnetic susceptibility data (Fig. 7) for $\left[\operatorname{Er}(\mathrm{tfa})_{3}(\right.$ bipy) $]$ and $\left[\mathrm{Er}(\mathrm{tpm})_{3}(\right.$ bipy) $]$ collected under a $100 \mathrm{G}$ applied field reveal that the room-temperature value $\chi_{\mathrm{M}} T$ for $\left[\operatorname{Er}(\mathrm{tfa})_{3}(\right.$ bipy)] agrees with the paramagnetic value expected for $J=15 / 2$ (11.48 emu $\left.\mathrm{K} \mathrm{mol}^{-1}\right) \cdot{ }^{10} \mathrm{~A}$ larger difference is found for $\left[\operatorname{Er}(\mathrm{tpm})_{3}(\mathrm{bipy})\right]$; the experimental value (10.7 emu $\mathrm{K} \mathrm{mol}^{-1}$ ) was the first indication of the sample non-purity. The experimental powder diffractogram matches the predicted diffractogram from the single crystal structural model and no extra crystalline phase is visible. ${ }^{12}$ A quick X-ray fluorescence run showed some traces of $\mathrm{K}$ and most likely amorphous potassium nitrate/hydroxide is mixed with our sample.

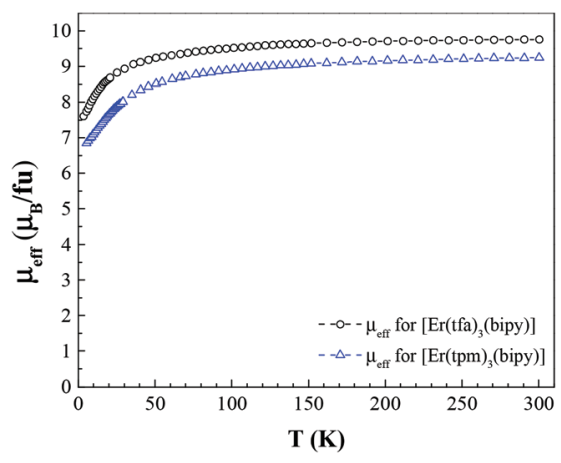

Fig. 7 Static magnetic properties of the erbium complexes: plots of $\mu_{\text {eff }}$ in the $3.55-300 \mathrm{~K}$ range and $\mathrm{DC}$ field of $100 \mathrm{G}$. 
As the temperature is lowered, the $\chi_{\mathrm{M}} T$ products decrease as a result of the depopulation of the Stark levels split by the ligand field.

Dynamic magnetic properties. For $\left[\operatorname{Er}(\mathrm{tfa})_{3}(\mathrm{bipy})\right]$ no appreciable opening of the magnetic hysteresis can be observed (Fig. S9†), but for $\left[\operatorname{Er}(\operatorname{tpm})_{3}\right.$ (bipy)] such an opening is clearly visible at $1.8 \mathrm{~K}$ (Fig. 8). Its hysteresis shape reveals strong field dependence. The loop displays no remnant magnetization as the magnetic moment of the sample rapidly falls to zero upon removal of the magnetic field.

The magnetization dynamics of both complexes were probed using AC measurements. In the absence of a static field, no maxima at the out-of-phase $\left(\chi^{\prime \prime}\right)$ component of the AC susceptibility could be observed for $\left[\mathrm{Er}(\mathrm{tfa})_{3}(\mathrm{bipy})\right]$ (Fig. S10 $\dagger$ ). On the other hand, for $\left[\operatorname{Er}(\operatorname{tpm})_{3}\right.$ (bipy)], (Fig. 9), the data reveal strong frequency-dependent out-of-phase signals below $6 \mathrm{~K}$.

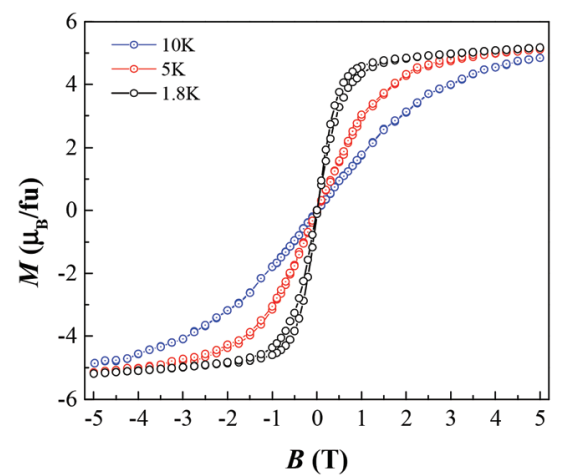

Fig. 8 Hysteresis loops at different temperatures for $\left[\operatorname{Er}(\operatorname{tpm})_{3}(\right.$ bipy $\left.)\right]$.
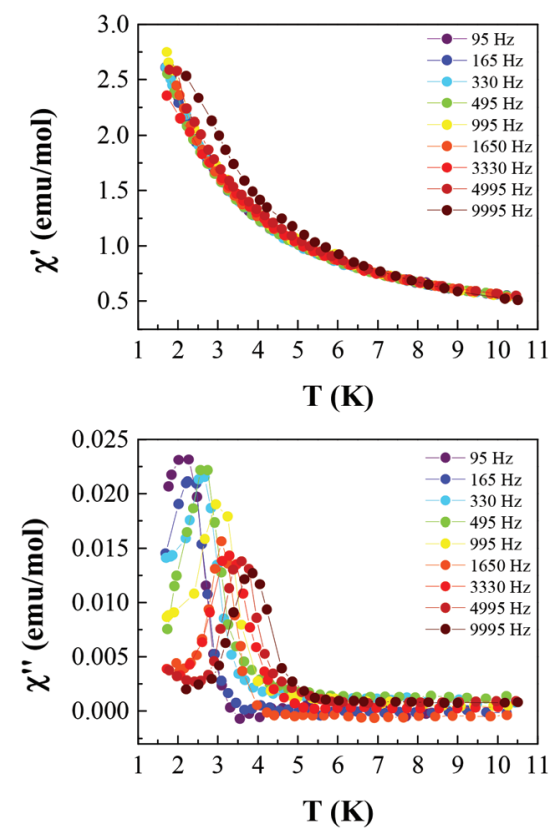

Fig. 9 In-phase (top) and out-of-phase (bottom) components of the AC susceptibility at different frequencies in the 1.7-8.45 $\mathrm{K}$ temperature range for $\left[\mathrm{Er}(\mathrm{tpm})_{3}(\right.$ bipy) $]$ complex. $H_{\mathrm{AC}}=5 \mathrm{Oe} ; H_{\mathrm{DC}}=0 \mathrm{Oe}$.
The intensities of the signals increase with decreasing temperature and frequency. Such performance clearly indicates slow relaxation of the magnetization associated with single-ion magnetism.

In order to obtain the relaxation energy barrier and the relaxation time, the peak temperature $T$ may be obtained by fitting the Gaussian peak function to the plot of $\chi^{\prime \prime} v s . T$, and the plot of $1 / T v s . \ln (\tau)$, based on the Arrhenius law $1 / T=-k_{\mathrm{B}} / U$ $\left[\ln (\tau)+\ln \left(\tau_{0}\right)\right]$, obeys a linear correlation, where $\tau$ is the relaxation time. The best fit yields the energy barrier $U / k_{\mathrm{B}}=21 \mathrm{~K}$ and the pre-exponential factor $\tau_{0}=7.9 \times 10^{-8} \mathrm{~s}$.

With the application of a $1000 \mathrm{G}$ static magnetic field, expected to reduce the Quantum Tunneling of Magnetization (QTM) through spin-reversal barrier via degenerate $\pm M_{\mathrm{S}}$ levels, both compounds show in-phase $\left(\chi^{\prime}\right)$ and out-of-phase $\left(\chi^{\prime \prime}\right)$ signals with a frequency dependence at 1.7-10 K (Fig. 10 and 11). The AC signal is much weaker for $\left[\operatorname{Er}(\operatorname{tfa})_{3}(\right.$ bipy $\left.)\right]$, but the maximum can still be followed with temperature. Using $\chi(\omega)$, magnetization relaxation times could be extracted and an Arrhenius law fit could be applied to yield a temperature of $14.8 \mathrm{~K}$ as the energy barrier. At lower temperatures an independent regime of the relaxation time of magnetization is observed.

Fig. 12 and 13 portray the Cole-Cole diagrams in the temperature range 1.7-5 K. For $\left[\mathrm{Er}(\mathrm{tfa})_{3}(\right.$ bipy) $]$ such diagrams exhibit semi-circular shapes and can be fitted using the generalized Debye model, affording $\alpha$ values in the range $0.01-0.15$ (see Table 5), which support the existence of a single relaxation process.
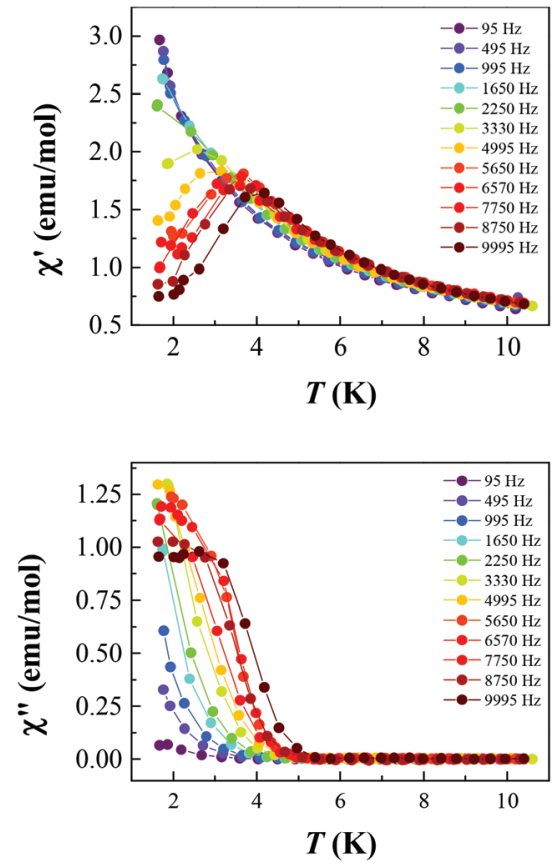

Fig. 10 In-phase (top) and out-of-phase (bottom) components of the $A C$ susceptibility of $\left[\mathrm{Er}(\mathrm{tfa})_{3}(\mathrm{bipy})\right]$ complex at different frequencies and at $1000 \mathrm{G} \mathrm{DC}$ field in the $1.7-10.6 \mathrm{~K}$ temperature range. 

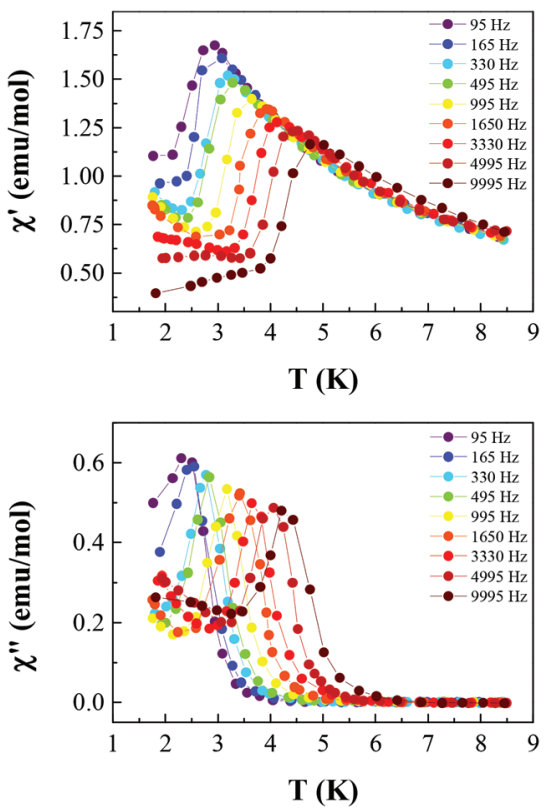

Fig. 11 In-phase (top) and out-of-phase (bottom) components of the AC susceptibility at different frequencies in the 1.7-8.45 K temperature range for the $\left[\mathrm{Er}(\mathrm{tpm})_{3}(\right.$ bipy $\left.)\right]$ complex. $H_{\mathrm{AC}}=5 \mathrm{Oe} ; H_{\mathrm{DC}}=1000 \mathrm{Oe}$.

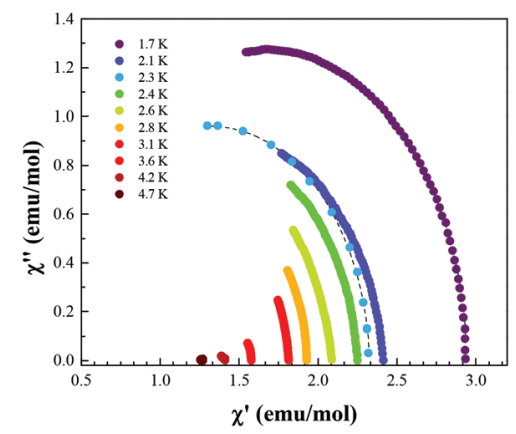

Fig. 12 Argand diagrams and Debye fittings for the [Er(tfa $)_{3}($ bipy $\left.)\right]$ complex. $H_{\mathrm{AC}}=5$ Oe; $H_{\mathrm{DC}}=1000 \mathrm{Oe}$.

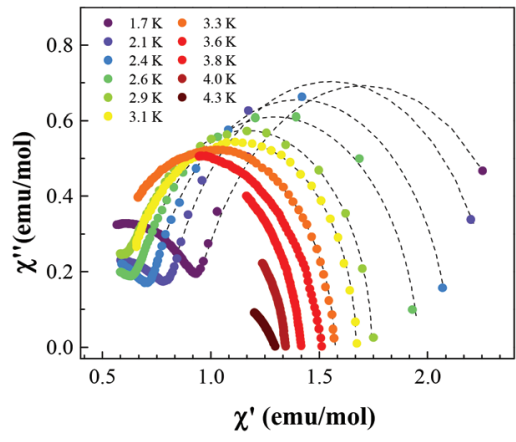

Fig. 13 Argand diagrams and Debye fittings for the $\left[\mathrm{Er}(\mathrm{tpm})_{3}(\mathrm{bipy})\right]$ complex. $H_{\mathrm{AC}}=5 \mathrm{Oe} ; H_{\mathrm{DC}}=1000 \mathrm{Oe}$.
Table 5 Generalized Debye model fitting parameters from 1.7 to $3.6 \mathrm{~K}$ for $\left[\operatorname{Er}(\mathrm{tfa})_{3}(\right.$ bipy) $]$

\begin{tabular}{lllll}
\hline$T(\mathrm{~K})$ & $\chi_{\mathrm{a}}$ & $\chi_{\mathrm{T}}$ & $\alpha$ & $\tau$ \\
\hline 1.7 & 0.35 & 2.94 & 0.01 & $3.490 \times 10^{-5}$ \\
2.1 & 0.30 & 2.42 & 0.08 & $1.929 \times 10^{-5}$ \\
2.3 & 0.32 & 2.33 & 0.03 & $1.635 \times 10^{-5}$ \\
2.4 & 0.27 & 2.25 & 0.06 & $1.493 \times 10^{-5}$ \\
2.6 & 0.14 & 2.08 & 0.08 & $9.421 \times 10^{-6}$ \\
2.8 & 0.33 & 1.93 & 0.05 & $7.577 \times 10^{-6}$ \\
3.1 & 0.30 & 1.82 & 0.07 & $4.922 \times 10^{-6}$ \\
3.6 & 0.73 & 1.58 & 0.15 & $1.954 \times 10^{-6}$
\end{tabular}

For $\left[\operatorname{Er}(\operatorname{tpm})_{3}(\right.$ bipy) $]$, two distorted semicircles are seen corresponding to two different relaxation times at temperatures below $2.9 \mathrm{~K}$. To determine the distribution of relaxation processes, for each relaxation mechanism, we fitted the complex susceptibility on the basis of a linear combination of two modified Debye models (Table 6),

$$
\chi_{\text {total }}^{*}=\chi_{\mathrm{S}}+\left(\chi_{\mathrm{T}}-\chi_{\mathrm{S}}\right)\left[\frac{\beta}{1+\left(\mathrm{i} \omega \tau_{\mathrm{FR}}\right)^{1-\alpha_{\mathrm{FR}}}}+\frac{1-\beta}{1+\left(\mathrm{i} \omega \tau_{\mathrm{SR}}\right)^{1-\alpha_{\mathrm{SR}}}}\right]
$$

The average value of the $\beta$ parameter is 0.72 , meaning that the ratio between the two relaxation mechanisms is $0.72: 0.28$. At $1.7 \mathrm{~K}$, the low temperature relaxation is circa 100 times faster than the relaxation mechanism that subsists at higher temperatures $\left(3 \times 10^{-5}\right.$ versus $5 \times 10^{-3} \mathrm{~s}$ as relaxation times $)$. With increasing temperatures, the relaxation time of the latter mechanism is progressively smaller (Table 6).

The Arrhenius analysis gives the effective energy barriers of $U=8.7 \mathrm{~K}$ at $40.1 \mathrm{~K}$ and pre-exponential factors of $4.75 \times 10^{-7}$ and $2.85 \times 10^{-10} \mathrm{~s}$ for the low temperature and high temperature domains, respectively.

For both regimes, there is evidence of approaching a temperature-independent regime of the relaxation time of magnetization since the linearity of the Arrhenius plot is lost at the lowest temperatures (Fig. 14).

The $\left[\operatorname{Er}(\operatorname{tpm})_{3}(\right.$ bipy) $]$ complex shows a rich and complex magnetic behaviour. One energy barrier is found at 0 DC field and two extra barriers are found in a 1000 Gauss DC field. The difference in energy after field application, $\Delta U=2 \times \mu \times B{ }^{2}$ is just in the order of the tenths of kelvin and cannot explain such a difference in the energy barrier.

Usually the existence of several relaxation mechanisms has been attributed to different environments of the lanthanide ion, such as different crystallographic sites in a polynuclear cluster or coordinating ligand disorder., ${ }^{9,18}$ The $\left[\mathrm{Er}(\mathrm{tpm})_{3}(\right.$ bipy) $]$ complex shows some disorder but not in the inner coordination sphere, and the same happens to $\left[\mathrm{Er}(\mathrm{tfa})_{3}(\right.$ bipy) $]$. In fact, in $\left[\operatorname{Er}(\mathrm{tfa})_{3}\right.$ (bipy)], there is not only disorder on the fluorine atom positions but also a rotation of $180^{\circ}$ of the furyl ring around the $\mathrm{C}-\mathrm{C}$ bond that attaches this group to the central $\beta$-diketonate moiety. If disorder in the second coordination sphere is to explain the existence of several relaxation mechanisms, why do such mechanisms exist 
Table 6 Modified Debye model fitting parameters from 1.7 to $4.3 \mathrm{~K}$ for $\left[\mathrm{Er}(\mathrm{tpm})_{3}(\mathrm{bipy})\right]$

\begin{tabular}{|c|c|c|c|c|c|c|c|}
\hline$T(\mathrm{~K})$ & $\chi_{\mathrm{s}}$ & $\chi_{\mathrm{T}}$ & $\tau_{1}[\mathrm{~s}]$ & $\alpha_{1}$ & $\tau_{2}[\mathrm{~s}]$ & $\alpha_{2}$ & $\beta$ \\
\hline 1.7 & 0.241 & 2.489 & $5.320 \times 10^{-3}$ & $7.884 \times 10^{-2}$ & $3.457 \times 10^{-5}$ & $6.479 \times 10^{-2}$ & 0.692 \\
\hline 2.1 & 0.311 & 2.315 & $3.520 \times 10^{-3}$ & $4.924 \times 10^{-2}$ & $2.897 \times 10^{-5}$ & $9.933 \times 10^{-2}$ & 0.752 \\
\hline 2.4 & 0.243 & 2.100 & $1.850 \times 10^{-3}$ & $3.844 \times 10^{-2}$ & $1.842 \times 10^{-5}$ & $6.978 \times 10^{-2}$ & 0.742 \\
\hline 2.6 & 0.234 & 1.959 & $8.744 \times 10^{-4}$ & $5.317 \times 10^{-2}$ & $1.326 \times 10^{-5}$ & $4.615 \times 10^{-2}$ & 0.760 \\
\hline 2.9 & 0.034 & 1.743 & $3.746 \times 10^{-4}$ & $1.770 \times 10^{-3}$ & $8.745 \times 10^{-6}$ & $3.941 \times 10^{-2}$ & 0.654 \\
\hline 3.1 & 0.581 & 1.670 & $1.482 \times 10^{-4}$ & $1.550 \times 10^{-3}$ & - & - & 1 \\
\hline 3.3 & 0.467 & 1.574 & $7.452 \times 10^{-5}$ & $4.617 \times 10^{-2}$ & - & - & 1 \\
\hline 3.6 & 0.256 & 1.515 & $2.824 \times 10^{-5}$ & $1.286 \times 10^{-1}$ & - & - & 1 \\
\hline 3.8 & 0.255 & 1.417 & $1.421 \times 10^{-5}$ & $9.233 \times 10^{-2}$ & - & - & 1 \\
\hline 4.0 & 0.484 & 1.347 & $8.761 \times 10^{-6}$ & $1.503 \times 10^{-1}$ & - & - & 1 \\
\hline 4.3 & 0.732 & 1.300 & $3.858 \times 10^{-6}$ & $3.979 \times 10^{-1}$ & - & - & 1 \\
\hline
\end{tabular}
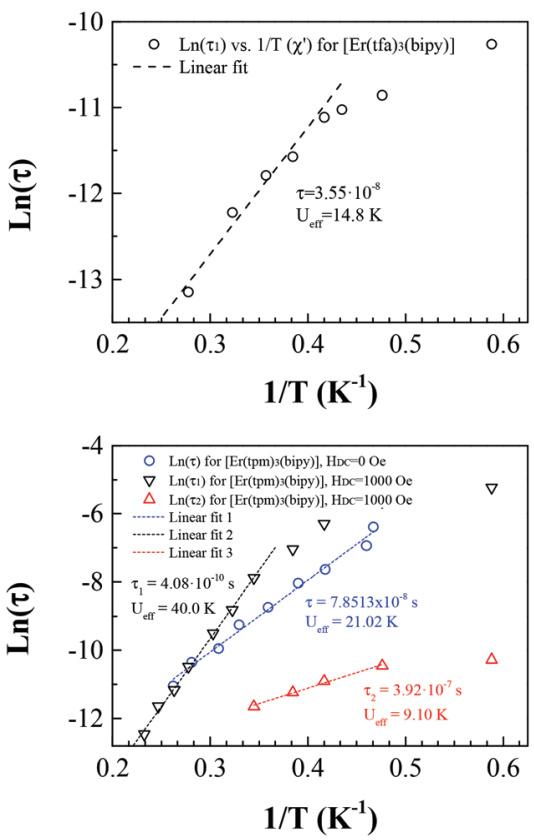

Fig. 14 Top: Arrhenius law fitting for the $\left[\operatorname{Er}(t f a)_{3}(b i p y)\right]$ complex. $H_{\mathrm{AC}}=5 \mathrm{Oe}, H_{\mathrm{DC}}=1000 \mathrm{Oe}$; bottom: Arrhenius law fittings for the [Er(tpm) $)_{3}\left(\right.$ bipy)] complex at $H_{\mathrm{DC}}=0$ Oe (blue) and $H_{\mathrm{DC}}=1000$ Oe (FR, black; $\mathrm{SR}, \mathrm{red}) . H_{\mathrm{AC}}=5 \mathrm{Oe}$ in all cases.

in $\left[\operatorname{Er}(\operatorname{tpm})_{3}(\right.$ bipy $\left.)\right]$ and not in $\left[\operatorname{Er}(\operatorname{tfa})_{3}(\right.$ bipy $\left.)\right]$ ? Another hypothesis to explain the existence of several relaxation pathways is the following:

- If the energy levels in the lanthanide system are distributed in a double well fashion, QTM between different levels may occur, and such tunneling could be promoted/hindered by the application of a very small field, changing faintly the energy level match/mismatch (Fig. 15).

- In such conditions, the total energy barrier would never be overcome.

- A correlation between the structural characteristics of the first coordination sphere around the lanthanide and the magnetic properties can be attempted. In previous studies, a tendency seemed to be emerging: in tris( $\beta$-diketonates $)(\mathrm{N}, \mathrm{N}$ donor)Ln(III) complexes, the bulkier the $\mathrm{N}, \mathrm{N}$-donor was, the higher the energy barrier was to overcome. ${ }^{8,19,20}$ An attempt to

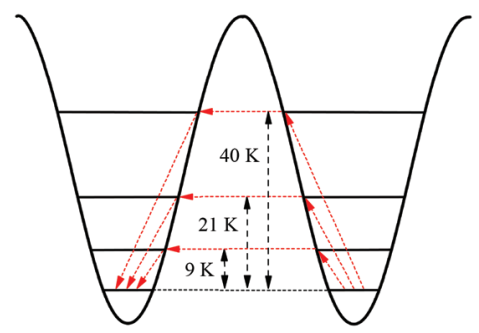

Fig. 15 Scheme representing the double well potential of the lanthanide ion to illustrate the possible phonon-assisted tunnelling paths and the associated energy barriers. Levels are shown at arbitrary positions.

obtain a more detailed magneto-structural correlation shows that for $\mathrm{Dy}^{3+}$ complexes the higher the skew angle the better, ${ }^{19}$ while for $\mathrm{Er}^{3+}$ it was the higher $\alpha$ value that provided the larger energy barrier. In this study we have found that the $\alpha$ angles are almost identical, so it is the higher $\phi$ value that delivered the richer magnetic properties. However, if one accepts that the reversal of the lanthanide magnetic moment is achieved through tunneling between several excited states, it becomes more difficult to establish simple magneto-structural correlations.

\section{Conclusions}

The magnetic properties of two similar mononuclear $\mathrm{Er}^{3+}$ complexes have been studied. One of the complexes, using 4,4,4trifluoro-1-(2-furyl)-1,3-butanedionate ligands, has been crystallised for the first time. Both complexes have similar square anti-prismatic coordination geometries around the lanthanide but show distinct magnetic properties. AC magnetic susceptibility measurements confirm that single-ion magnet behaviour is displayed in a zero DC magnetic field with a thermally activated barrier of $21 \mathrm{~K}$ for $\left[\operatorname{Er}(\operatorname{tpm})_{3}(\right.$ bipy)]. Upon the application of a static field, further relaxation mechanisms are observed: $\left[\operatorname{Er}(\mathrm{tfa})_{3}(\mathrm{bipy})\right]$ shows one weak thermally activated relaxation while $\left[\operatorname{Er}(\operatorname{tpm})_{3}(\right.$ bipy $\left.)\right]$ has two sets of thermally activated relaxations. Due to its ability to absorb energy in the ultra-violet and re-emit it with a sharp $1.5 \mu \mathrm{m}$ emission, $\left[\operatorname{Er}(\operatorname{tpm})_{3}(\right.$ bipy $\left.)\right]$ can be considered one of the rare examples of a bifunctional luminescent single-ion magnet. 


\section{Acknowledgements}

P.M.-R. would like to thank Iberdrola Foundation for their financial support and the General Research Support Service (SEGAI) at Universidad de La Laguna for the TG analysis. J.T.C. and P.S.P.S. acknowledge the support by Fundação para a Ciência e a Tecnologia (FCT) under the scholarship SFRH/BD/ $84628 / 2012$ and FRH/BPD/84173/2012. The CEMDRX group is grateful to FEDER (Programa Operacional Factores de Competitividade COMPETE) and from FCT-Fundação para a Ciência e a Tecnologia under the project PEst-C/FIS/UI0036/2014. Support by MICINN (MAT2010-21270-C04-02, MAT2013-46649C4-4-P, the Consolider-Ingenio 2010 Program MALTA CSD200700045 and the Spanish National Program of Infrastructure) and by EU-FEDER funds is gratefully acknowledged by the La Laguna group. The UVa group acknowledges financial support from the Junta de Castilla y León.

\section{Notes and references}

1 L. Bogani and W. Wernsdorfer, Nat. Mater., 2008, 7, 179; M. N. Leuenberger and D. Loss, Nature, 2001, 410, 789.

2 D. Gatteschi, R. Sessoli and J. Villain, Molecular nanomagnets, Oxford University Press, New York, 2006.

3 E. Ruiz, J. Cirera, J. Cano, S. Alvarez, C. Loose and J. Kortus, Chem. Commun., 2008, 52, DOI: 10.1039/ b714715e.

4 R. J. Blagg, C. A. Muryn, E. J. L. McInnes, F. Tuna and R. E. P. Winpenny, Angew. Chem., Int. Ed., 2011, 123, 6660 .

5 F. Branzoli, P. Carretta, M. Filibian, G. Zoppellaro, M. J. Graf, J. R. Galan-Mascaros, O. Fuhr, S. Brink and M. Ruben, J. Am. Chem. Soc., 2009, 131, 4387.

6 F. Pointillart, B. Le Guennic, T. Cauchy, S. Golhen, O. Cador, O. Maury and L. Ouahab, Inorg. Chem., 2013, 52, 5978; X.-Q. Zhao, X.-H. Liu, J.-J. Li and B. Zhao, CrystEngComm, 2013, 15, 3308; N. F. Chilton, S. K. Langley, B. Moubaraki, A. Soncini, S. R. Batten and K. S. Murray, Chem. Sci., 2013, 4, 1719; Z.-R. Jhu, C.-I. Yang and G.-H. Lee, CrystEngComm, 2013, 15, 2456; T. D. Pasatoiu, J.-P. Sutter, A. M. Madalan, F. Z. C. Fellah, C. Duhayon and M. Andruh, Inorg. Chem., 2011, 50, 5890; T. Kajiwara, M. Nakano, K. Takahashi, S. Takaishi and M. Yamashita, Chem. - Eur. J., 2011, 17, 196.
7 P. Martín-Ramos, M. Ramos Silva, J. T. Coutinho, L. C. J. Pereira, P. Chamorro-Posada and J. Martín-Gil, Eur. J. Inorg. Chem., 2014, 2014, 511.

8 M. Ramos Silva, P. Martín-Ramos, J. T. Coutinho, L. C. J. Pereira and J. Martín-Gil, Dalton Trans., 2014, 43, 6752.

9 S.-D. Jiang, B.-W. Wang, H.-L. Sun, Z.-M. Wang and S. Gao, J. Am. Chem. Soc., 2011, 133, 4730.

10 S.-D. Jiang, S.-S. Liu, L.-N. Zhou, B.-W. Wang, Z.-M. Wang and S. Gao, Inorg. Chem., 2012, 51, 3079.

11 J. J. Le Roy, I. Korobkov and M. Murugesu, Chem. Commun., 2014, 50, 1602.

12 P. Martín-Ramos, M. R. Silva, C. Coya, C. Zaldo, Á. L. Álvarez, S. Álvarez-García, A. M. Matos Beja and J. Martín-Gil, J. Mater. Chem. C, 2013, 1, 2725.

13 G. Sheldrick, SADABS, University of Göttingen, Göttingen, Germany, 1996.

14 G. M. Sheldrick, Acta Crystallogr., Sect. A: Found. Crystallogr., 2007, 64, 112.

15 A. L. Spek, J. Appl. Crystallogr., 2003, 36, 7.

16 L. Sorace, C. Benelli and D. Gatteschi, Chem. Soc. Rev., 2011, 40, 3092.

17 S. Gago, J. A. Fernandes, J. P. Rainho, R. A. Sá Ferreira, M. Pillinger, A. A. Valente, T. M. Santos, L. D. Carlos, P. J. A. Ribeiro-Claro and I. S. Gonçalves, Chem. Mater., 2005, 17, 5077 .

18 G. Cucinotta, M. Perfetti, J. Luzon, M. Etienne, P.-E. Car, A. Caneschi, G. Calvez, K. Bernot and R. Sessoli, Angew. Chem., Int. Ed., 2012, 51, 1606; K. Katoh, Y. Horii, N. Yasuda, W. Wernsdorfer, K. Toriumi, B. K. Breedlove and M. Yamashita, Dalton Trans., 2012, 41, 13582; P.-H. Lin, W.-B. Sun, M.-F. Yu, G.-M. Li, P.-F. Yan and M. Murugesu, Chem. Commun., 2011, 47, 10993; K. C. Mondal, A. Sundt, Y. Lan, G. E. Kostakis, O. Waldmann, L. Ungur, L. F. Chibotaru, C. E. Anson and A. K. Powell, Angew. Chem., Int. Ed., 2012, 51, 7550; M. A. AlDamen, S. Cardona-Serra, J. M. Clemente-Juan, E. Coronado, A. Gaita-Ariño, C. Martí-Gastaldo, F. Luis and O. Montero, Inorg. Chem., 2009, 48, 3467; P.-H. Lin, T. J. Burchell, L. Ungur, L. F. Chibotaru, W. Wernsdorfer and M. Murugesu, Angew. Chem., Int. Ed., 2009, 48, 9489.

19 Y. Bi, Y.-N. Guo, L. Zhao, Y. Guo, S.-Y. Lin, S.-D. Jiang, J. Tang, B.-W. Wang and S. Gao, Chem. - Eur. J., 2011, $17,12476$.

20 G.-J. Chen, Y.-N. Guo, J.-L. Tian, J. Tang, W. Gu, X. Liu, S.-P. Yan, P. Cheng and D.-Z. Liao, Chem. - Eur. J., 2012, 18, 2484. 